研究

\title{
直角分岐管のキャビテーション流れの研究*
}

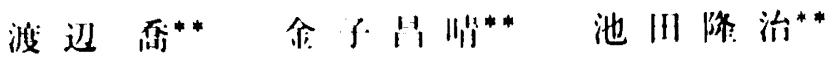

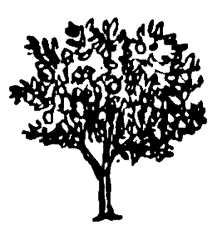

\section{Study of the Cavitation Flow due to a Right-Angled Branch Duct}

\author{
Takashi WATANABE, Masaharu KANEKO and Ryuji IKEDA
}

A theory was developed for cavitation flow in a two-dimensional right-angled branch duct. In analysis, the wake model was used. As a numerical example, the shape of the cavity streamline originating from the branch corner, the length of the cavity and the cavity height (thickness) were obtained for the values of $0.5,1.0$ and 2.0, which was the width ratio of the main duct to the lateral duct. The length and thickness of the resulting cavity were determined as a function of the cavitation parameter and the velocity of the lateral stream to the mainstream. That is, the length and thickness of the cavity increased as the cavitation parameter and the velocity ratio decreased, and as a result, the flow width of the lateral duct decreased. The cavitation parameters on the condition of the supercavitation were increased as the velocity ratio decreased, and these parameters agreed well with experimental results of the author's previous paper.

\section{1. 緒 言}

分岐合流管は管路網の結合要曼として種々の形式の あのが考えられ，てれまでにも数多く使用されてきて いる．てれら分岐合流管の流れについては，それぞれ の場合に応じ多くの研究がなされてきている(1) 6).し かし，流れの様相が複䧴であるため解決されない問題 る残っている，特に，分岐合流管において，流速が大 きくなった場合に分岐合流部の下流側にキャビテーシ ョンが発生するととがある. このキャビテーションの 発生により，鏹音が発生し，時には眍管系の振動の原 因となることあある。したがって、キャビテーション の発生条件，発生したキャビティの大きさや形状を知 るととは管路網を計画, 設計するにあたり必要なとと

* 昭和61年 3 月 27 日 原稿受付

**岩手大学工学部機械工学科（干 020 盛岡市上田 四丁目 3-5)
である．分岐合流管のキャビテーションに网する㫰告 としては，主管と支管との断面積の比か等しい通常 T

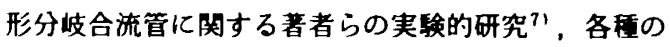
対向 T形分岐管，および通常Y形分岐管や断面栍比の 異なる通常 T形分岐管に威する藤原ら ${ }^{81,91}$ の実鈋的 研究がある.

本研究においては，二次元直角分岐管にキャビテー ションが発生した場合の流れの様相を明らかにする目 的のるとに，分岐部下流に発生するキ+ビティ流れに 対し，後流モデルを用いて理論解析を行った。数値計 算例として，分岐管の本管之支管の流路幅の比を 0.5 , $1.0 ， 2.0$ として，分流後の速度比が変化した場合につ いて，種々のキ+ビテーション係数に対するキ+ビテ ィの形状，長さ，厚さ，およびキャビティ発生による 支管の流路幅の収縮割合などを求めた。

\section{2. 基礎式}

二次元直角分岐管に有限長さのキャビティが発生し 
た场合の流れを费える、Fig. 1亿示す物理面（z面)に おいて，分岐簎の本管の上流扰よび下流の渴をそれぞ

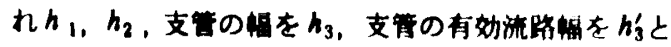

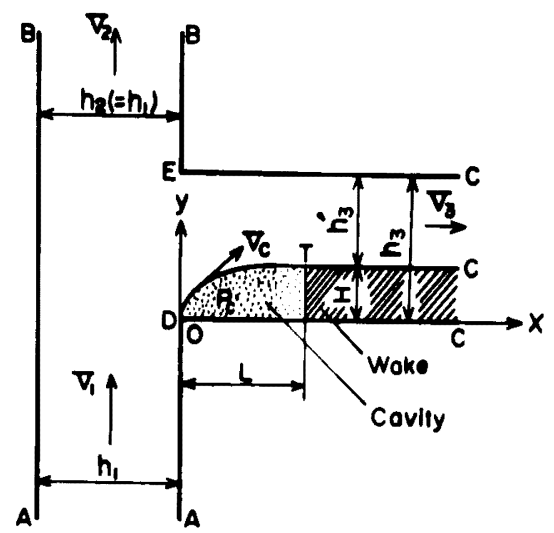

Fig. 1 Physical plane (z plane)

し，本管の上流枋よび下流の流违をそれぞれV、V、

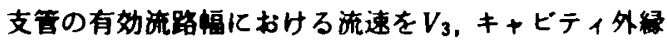
の流速を $V_{c}$ とする，今，本管の上流の圧力を $P_{1}, \neq+$ ビティ内部の圧力を $P_{c}$ とし,キャビテーション係数を 次のように定举する。

$$
\sigma=\frac{P_{1}-P_{c}}{\frac{1}{2} \rho V_{1}^{2}}
$$

こてに，ノは流体の密度を表わす。また。キ+ビティ 外绿での流速 $V_{c}$ は次式で表わされる。

$$
V_{c}=V_{1} \sqrt{1+\sigma}
$$

てのキ+ビティ流れに対し後流モデルを通用すると， 二次元直角分岐管内の流れの場は次式(3)で定戠される

$$
w=\frac{d W}{d z}=V e^{-i \theta}
$$

ホトグラフ面 ( $w$ 面) においてはFig. 2に示すような 4 分の 1 の円の内部に対応する，ててに，Vは物理面 での流速の大きさ， $\theta$ は $V$ の $x$ 軸とのなす角度である. さらに，乙の閉曲線の内部をキ+ビティ外緣での流速 $V_{c}$ を代表值にとり，次式(4)で定義されるく面に写像す ろ (Fig. 3 ).

$$
\zeta=w / V_{c}
$$

こてに

$$
v_{1}=V_{1} / V_{c}, v_{2}=V_{2} / V_{c}, v_{3}=V_{3} / V_{c} .
$$

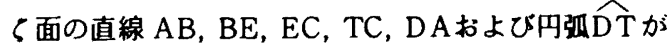
Z面のそれぞれの記号に対応した流線となる流れの場は

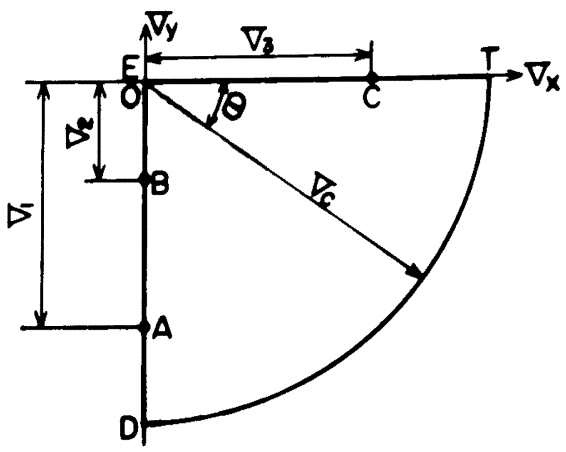

Fig. 2 Hodograph plane ( $w$ plane)

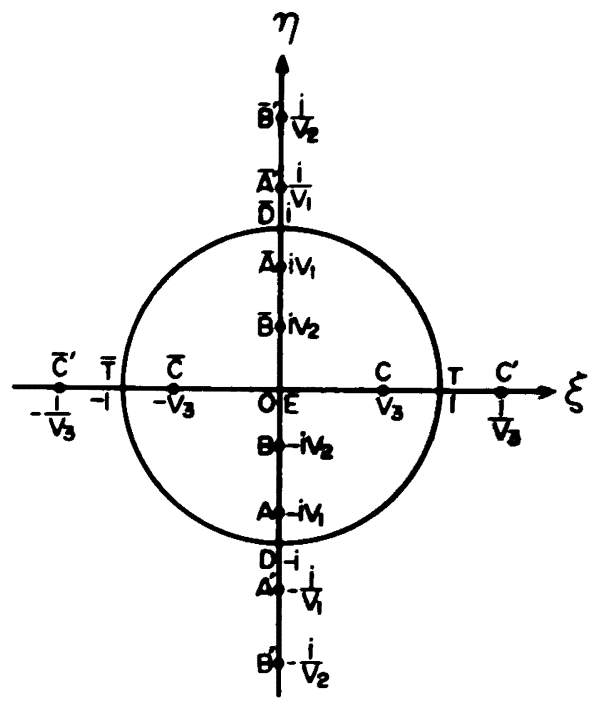

Fig. 35 plane

点A， $\mathrm{A}^{\prime}, \overline{\mathrm{A}}, \overline{\mathrm{A}}^{\prime}$ にそれぞれ强さ $m_{1}=2 h_{1} V_{1}$ の吹き出し，

点 $\mathrm{B}, \mathrm{B}^{\prime}, \overline{\mathrm{B}}, \overline{\mathrm{B}}^{\prime}$ にそれぞれ茧さ $m_{2}=2 h_{2} V_{2}$ の吸い込み，

点C， $\mathrm{C}^{\prime} 、 \overline{\mathrm{C}}, \overline{\mathrm{C}}^{\prime}$ にそれぞれ强さ

の吸い込み

$$
m_{3}=2\left(h_{1} V_{1}-h_{2} V_{2}\right)
$$

(6)

のある流れに相当する．したがって，ての流れの場の 複素ポテンシャルWは次式で与えられる.

$$
\begin{aligned}
W & =\frac{m_{1}}{2 \pi} \log _{e}\left(\zeta-i v_{1}\right)\left(\zeta-\frac{i}{v_{1}}\right)\left(\zeta+i v_{1}\right)\left(\zeta+\frac{i}{v_{1}}\right) \\
& -\frac{m_{2}}{2 \pi} \log _{e}\left(\zeta-i v_{2}\right)\left(\zeta-\frac{i}{v_{2}}\right)\left(\zeta+i v_{2}\right)\left(\zeta+\frac{i}{v_{2}}\right)
\end{aligned}
$$


$-\frac{m_{3}}{2 \pi} \log _{e}\left(\zeta-v_{3}\right)\left(\zeta-\frac{1}{v_{3}}\right)\left(\zeta+v_{3}\right)\left(\zeta+\frac{1}{v_{3}}\right)$

$\cdot(7)$

また，透鈢の式は次式で表わされる。

$h_{1} v_{1}=h_{2} v_{2}+h_{3}^{\prime} v_{3}$

\section{3. キャビティの形状}

式(3)および式(4)より次式が求まる。

$$
d z=\frac{1}{V_{c} \zeta} \frac{d W}{d \zeta} d \zeta
$$

今, 式(7)の成係を用いて式(9)を䅡分し， $\zeta=e^{i \theta}$ の関 係を代入すると，次式 $z$ が求まる.

$$
\begin{aligned}
z= & \frac{h_{1}}{i \pi}\left\{\frac{1}{2}\left(1+v_{1}^{2}\right) \log _{e} \frac{1-2 v_{1} \sin \theta+v_{1}^{2}}{1+2 v_{1} \sin \theta+v_{1}^{2}}\right. \\
& \left.-i\left(1-v_{1}^{2}\right) \tan ^{-1} \frac{2 v_{1} \cos \theta}{1-v_{1}^{2}}\right\} \\
& -\frac{h_{2}}{i \pi}\left\{\frac{1}{2}\left(1+v_{2}^{2}\right) \log _{e} \frac{1-2 v_{2} \sin \theta+v_{2}^{2}}{1+2 v_{2} \sin \theta+v_{2}^{2}}\right. \\
& \left.-i\left(1-v_{2}^{2}\right) \tan ^{-1} \frac{2 v_{2} \cos \theta}{1-v_{2}^{2}}\right\} \\
& -\frac{h_{3}}{\pi}\left\{\frac{1}{2}\left(1+v_{3}^{2}\right) \log _{e} \frac{1-2 v_{3} \cos \theta+u_{3}^{2}}{1+2 v_{3} \cos \theta+u_{3}^{2}}\right. \\
& \left.+i\left(1-v_{3}^{2}\right) \tan ^{-1} \frac{2 v_{3} \cos \theta}{1-v_{3}^{2}}\right\}
\end{aligned}
$$$$
+A+i B
$$

こてに，Aおよび $B$ は定数である. 式10ににおいて， $z$ を実部と虚部とに分りると $z=x+i y$ となり，てれよ り $x$ およびyを求めることができる. 定数 $A$ およ゙ $B$ を決定するため， $z$ 面での $D$ 点を原点にとり， $\zeta=$ $-i(\theta=-\pi / 2)$ のとき, $z_{D}=x_{D}+i y_{D}=0$ とお くと $x_{D}=0, y_{D}=0$ より，定数 $A$ およ゙ $B$ は次式で表 わすととができる.

$$
\begin{aligned}
A= & 0 \\
B= & \frac{h_{1}}{\pi}\left(1+v_{1}^{2}\right) \log _{e} \frac{1+v_{1}}{1-v_{1}}-\frac{h_{2}}{\pi}\left(1+v_{2}^{2}\right) \times \\
& \log _{e} \frac{1+v_{2}}{1-v_{2}}-\frac{h_{3}^{\prime}}{\pi}\left(1-v_{3}^{2}\right) \tan ^{-1} \frac{2 v_{3}}{1-v_{3}^{2}} \cdots \cdots \text { (12) }
\end{aligned}
$$

てれよりキャビティの形状は次式 $x$ および $y$ より求 めるてとができる.

$$
\begin{aligned}
x= & -\frac{h_{1}}{\pi}\left(1-v_{1}^{2}\right) \tan ^{-1} \frac{2 v_{1} \cos \theta}{1-v_{1}^{2}} \\
& +\frac{h_{2}}{\pi}\left(1-v_{2}^{2}\right) \tan ^{-1} \frac{2 v_{2} \cos \theta}{1-v_{2}^{2}} \\
& -\frac{h_{3}^{\prime}}{\pi}\left(1+v_{3}^{2}\right) \log _{e} \frac{1-2 v_{3} \cos \theta+v_{3}^{2}}{1+2 v_{3} \cos \theta+v_{3}^{2}} \cdots-(13)
\end{aligned}
$$

$$
\begin{aligned}
y= & -\frac{h_{1}}{2 \pi}\left(1+v_{1}^{2}\right) \log _{\theta} \frac{1-2 v_{1} \sin \theta+v_{1}^{2}}{1+2 v_{1} \sin \theta+v_{1}^{2}} \\
& +\frac{h_{2}}{2 \pi}\left(1+v_{2}^{2}\right) \log _{\frac{1}{1}} \frac{1-2 v_{2} \sin \theta+v_{2}^{2}}{1+2 v_{2} \sin \theta+v_{2}^{2}} \\
& -\frac{h_{3}^{\prime}}{\pi}\left(1-v_{3}^{2}\right) \tan ^{-1} \frac{2 v_{3} \sin \theta}{1-v_{3}^{2}} \\
& +\frac{h_{1}}{\pi}\left(1+v_{1}^{2}\right) \log _{e} \frac{1+v_{1}}{1-v_{1}} \\
& -\frac{h_{2}}{\pi}\left(1+v_{2}^{2}\right) \log _{e} \frac{1+v_{2}}{1-v_{2}} \\
& -\frac{h_{3}^{\prime}}{\pi}\left(1-v_{3}^{2}\right) \tan ^{-1} \frac{2 v_{3}}{1-v_{3}^{2}}
\end{aligned}
$$

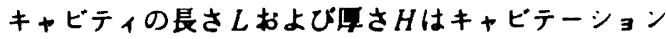
の消堿点 $T$ に扔いて $x_{0-0}+i y_{0-0}=L+i H$ の 成係より次式で表わされる.

$$
\begin{aligned}
& L=\frac{h_{1}}{\pi}\left(v_{1}^{2}-1\right) \tan ^{-1} \frac{2 v_{1}}{1-v_{1}^{2}}-\frac{h_{2}}{\pi}\left(v_{2}^{2}-1\right) \tan ^{-1} \frac{2 v_{2}}{1-v_{2}^{2}} \\
& -\frac{h_{3}^{\prime}}{\pi}\left(1+v_{3}^{2}\right) \log _{6} \frac{1-v_{3}}{1+v_{3}} \\
& H=-\frac{h_{1}}{\pi}\left(1+v_{1}^{2}\right) \log _{e} \frac{1-v_{1}}{1+v_{1}} \\
& +\frac{h_{2}}{\pi}\left(1+v_{2}^{2}\right) \log _{e} \frac{1-v_{2}}{1+v_{2}} \\
& +\frac{h^{\prime}}{\pi}\left(v_{3}^{2}-1\right) \tan ^{-1} \frac{2 v_{3}}{1-v_{3}^{2}}
\end{aligned}
$$

また，支管の流れの収緗係数 $C_{c}\left(h_{3}^{\prime} / h_{3}\right)$ はキ+ヒ ティの消减位霬 $T$ ，すなわち $\theta=0$ 亿おいて。

$y_{0-0}=H=h_{3}-h_{3}^{\prime}$ の関係より次式で表わされる.

$$
\begin{aligned}
C_{c}= & \left\{1+\frac{\lambda}{\pi}\left(1+v_{1}^{2}\right) \log _{e} \frac{1-v_{1}}{1+v_{1}}-\right. \\
& \left.\frac{1}{\pi} \frac{h_{2}}{h_{3}}\left(1+v_{1}^{2}\right) \log _{e} \frac{1-v_{2}}{1+v_{2}}\right\} / \\
& \left\{1+\frac{1}{\pi}\left(v_{3}^{2}-1\right) \tan ^{-1} \frac{2 v_{3}}{1-v_{3}^{2}}\right\}
\end{aligned}
$$

今, $h_{1} / h_{3}=\lambda, h_{2} v_{2} / h_{1} v_{1}=k$ とおく. とてでは， $h_{1}=h_{2}$ より $k=v_{2} / v_{1}$ を表わす. とれより，式(8)の 連続の式と式はのの保より，次式が求まる。

$$
\begin{aligned}
& \frac{1}{\lambda}=\frac{v_{1}}{v_{3}}(1-k)\left\{1+\frac{1}{\pi}\left(v_{3}^{2}-1\right) \tan ^{-1} \frac{2 v_{3}}{1-v_{3}}\right\} \\
& -\frac{1}{\pi}\left(1+v_{1}^{2}\right) \log _{e} \frac{1-v_{1}}{1+v_{1}} \\
& +\frac{1}{\pi}\left(1+v_{1}^{2} k^{2}\right) \log _{e} \frac{1-v_{1} k}{1+v_{1} k}
\end{aligned}
$$

てれより， $\sigma ， k ， \lambda の$ 值を与えると式(2)および(5)の関 係から $v_{1}$ が求まり，さらに，式(182より $v_{3}$ が求まる.乙 れよりキ+ピティの形状，長さ，厚さおよび支管の流 


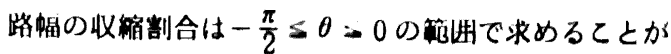
できる。

\section{4. 数值計算結果}

数値計算例として，直角分岐管の本管と支管の流路 帞比 $\lambda=h_{1} / h_{3}$ が $0.5 ， 1.0 ， 2.00$ 埸合につき，流 速比 $k=v_{2} / v_{1}$ およびキ+ビテーション係数 $の$ が変化

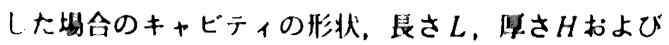
支流側の流九の收解係数 $C_{c}$ を水め大，得られたキャ ビィの形状をFig. 4 〜Fig. 7 亿示す. 国から明ら かなようにキャビテーション係数のが小さくなる にしたがいキ+ビティの艮さおよび厘さは人きくなり，

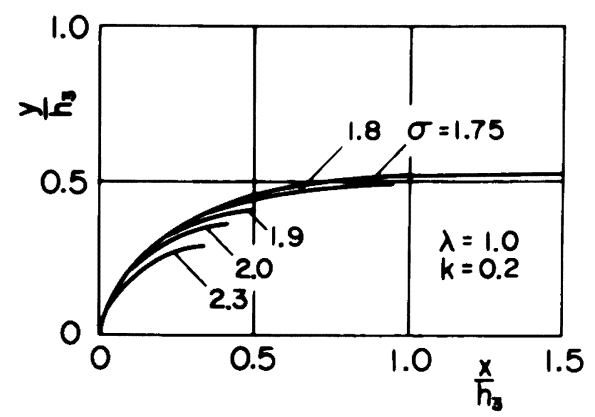

Fig. 4 Shape of cavity

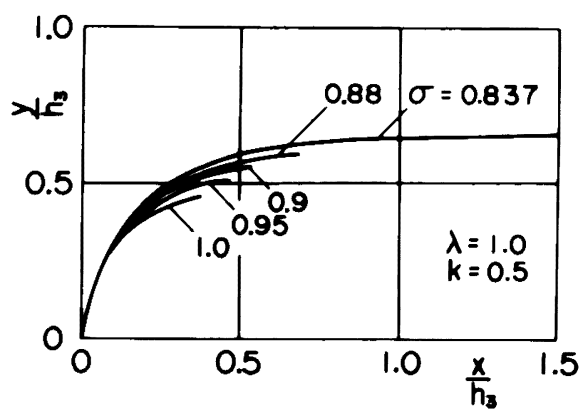

Fig. 5 Shape of cavity

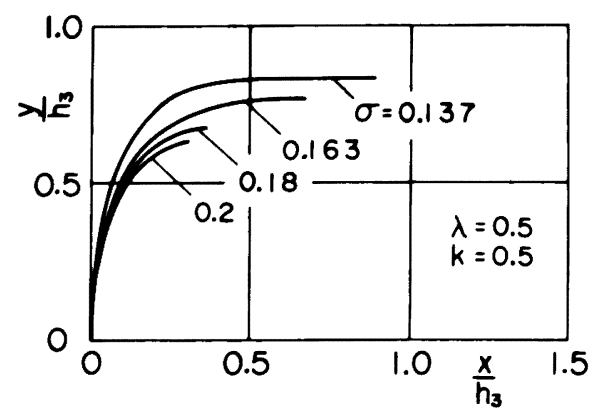

Fig. 6 Shape of cavity
ある值に連するとスーパーキャビテーションの状惢に なる.

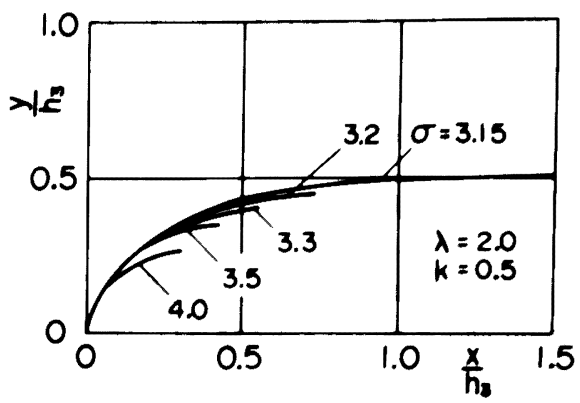

Fig. 7 Shape of cavity

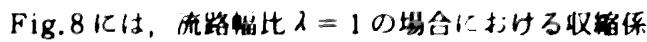
数 $C_{c}$ とキャビテーション係数のとの関係を示している. 四より収解係数 $C_{c}$ はキャビテーンョン保数のおよひ速

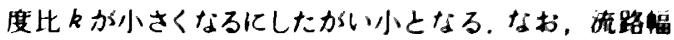

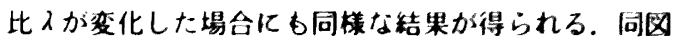
におりる点線はスーパーキャビテーション状腎におり る値を示す。

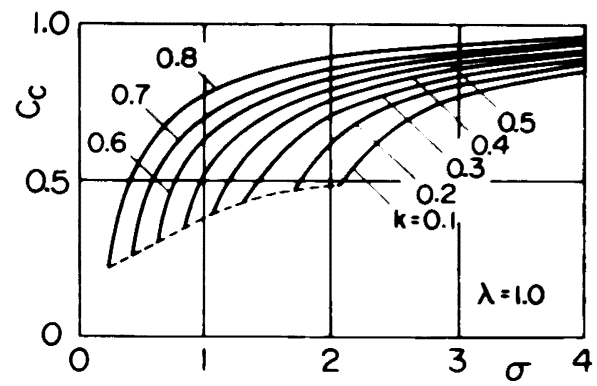

Fig. 8 Effective flow width in lateral duct $\mathrm{C}_{\mathrm{c}}$ to caviation parameter $\sigma$

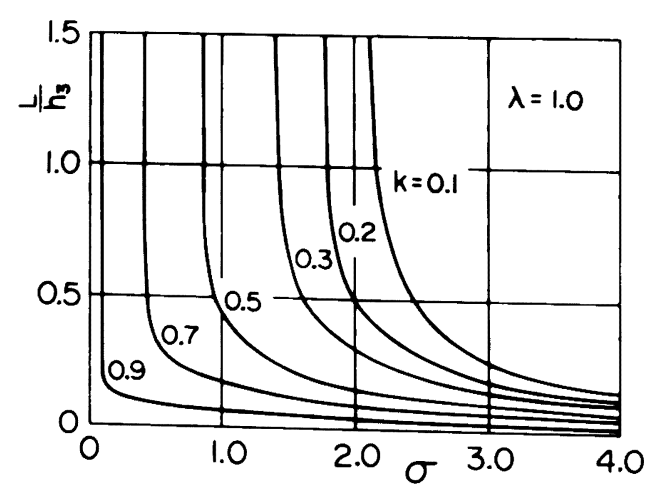

Fig. 9 Length of cavity $L$ as cavitation parameter $\sigma$ 


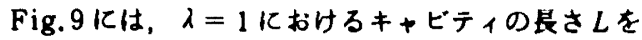
速度比kをバラメータにとり,キ+ビテーション係数 $\sigma$ との成係で表している。图から明らかなように，中 十ビテーション係数のおよび速度比 $k$ が小さくなるに したがいキ+ビティの長さしは大きくなりののある值 でスーパーキ+ビテーションの状点となる．流路愢入 が変化した埸合にも長さ LはFig. 9 と同様な関係で表 わされろ.

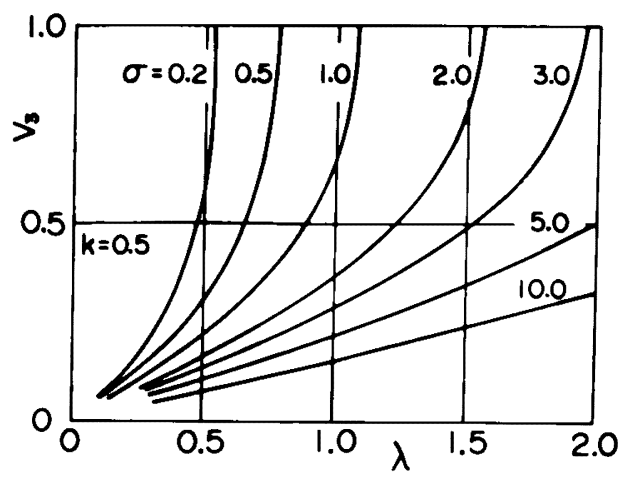

Fig. 10 Velocity $v_{3}$ versus duct width ratio $\lambda$

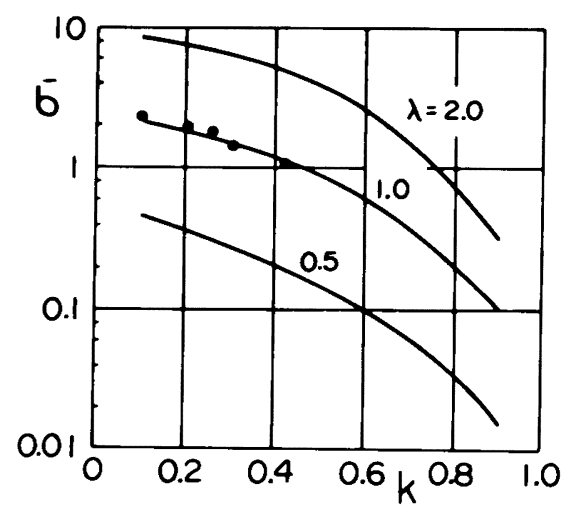

Fig. 11 Cavitation parameter $\sigma_{1}$ to velocity ratio $k$

(•: Experimental points ${ }^{7)}$ )

Fig.10はキャビテーション係数のをパラメータにと り $v_{3}$ と久との関係を示している， $v_{3} \leqq 1$ であり, 同 図加各流路幅比入に対しキャビテーション係数に限 界があるととがわかる.すなわち，各流路幅比入にお いて, $v_{3}=1$ の場合のキャビテーション係数の值はス 一パーキャビテーション状態の値を示す，今，ての状 態でのキャビテーション係数 $\sigma_{1}$ を梳みとり速度比 $k$ との関係をFig.11に示す.同図には実験により得られ

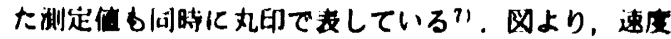
比kが小さくなるにしたがいスーパーキ+ピテーショ

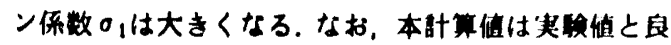

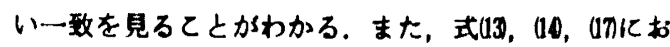
いて， $v_{3}=1$ とした堨合の式は茫浪らかの直角分岐管

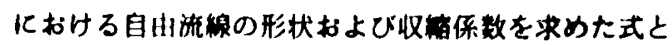
一致するととになる。

\section{5. 結}

直角分岐管に発生するキャビテーションの棁相を明 らかにする目的のるとに，流路内のキ+ピティ流れに 対し後流モデルを通用し理端を展開した，数值計萛例 として，本管と支管の流路幅の比か $0.5 ， 1.0 ， 2.0$ の 堨合につき，分岐部下流に発生するキャピティの形状， 長さ，厚さおよびキ+ビティによる支流側の流路愊の 収縮割合を理々の速度比 $k$ およびキャビテーション俰 数。の値に対し求めた．数值計算より得られた結果を 要約すると次のようになる。

1）キャビテーション係数のが小さくなるにしたが いキャビティの長さおよび厚さは大きくなり支流側の 有効流路愊は诚少する。

2）キ+ピテーション係数のが一定の場合, 速度比

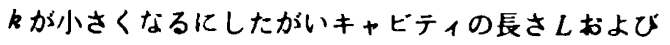
厚さHは大きくなり収編俰数C、は小となる。

3）スーパーキ+ピテーションの状態におりるキャ ビテーション係数の、速度比 $k$ が小さくなるにしたが い大きくなる，なお，計算により得られたの、の值は実 段値と良い一致を見る。

\section{考文献}

1）松本，葛西：二つの水流の行奖传了損失，機械 学会誌, 33-157，284 / 299 (1930)

2）沖，川口：分岐および合流管の水頭損失に対する 考察，日本機械学会論文集，17-60，146/151 (1951)

3）新律，倉橋：直角分岐管の分流および合流特性、

術生工業協会誌，30-2，86/91（1956）

4）佐藤：長方形断面の分岐および合流管の損失に関 する実呀，日本機械学会論文集，28-192，881／ 890 (1967)

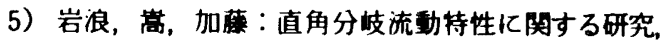
日本機械学会論文集，35-269，97／106（1969）

6）池田，渡忍：直角合流管（ $\mathrm{T}$ 字管）のはく離を件 う流れの計算, 岩手大学工学部報告, $19,23 / 28$ (1966)

7）池田，渡辺：分岐合流管のキャビテーションに関 


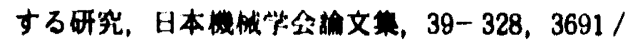
3698 (1973)

8 湶，門はか：対问丁形分岥管におけるキャビテ

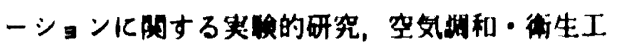
学会给文集, 9, 63/72 (1979)

9 原，門，細川：分岐管におりるキ+ビテーシ.

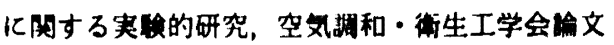

集, 15, 33 / 45 (1981) 